\title{
"HOUSE NEPAL" PROJECT: INITIAL RESULTS AND PERSPECTIVES FOR AN ANTI-SEISMIC COOPERATION PROJECT
}

\author{
F. Vegas ${ }^{1,2, *}$, C. Mileto ${ }^{1,2}$, L. García ${ }^{1,2}$, V. Cristini ${ }^{1,2}$ \\ ${ }^{1}$ Department of Architectural Composition, Universitat Politècnica de València, Valencia, Spain - (fvegas, cami2, \\ vacri)@cpa.upv.es, ligarso@upv.es \\ ${ }^{2}$ Research Centre PEGASO, Universitat Politècnica de València, Valencia, Spain
}

Commission II - WG II/8

KEY WORDS: Development and cooperation, SDG, Earthen architecture, Prototype, Seismic prevention

\begin{abstract}
:
The "HouSe-Nepal" project is being developed within the framework of the ADSIDEO programme (Project for the Centre for Development Cooperation of Universitat Politècnica de València 2018-2020) in collaboration with the Nepalese foundation Abari: Bamboo and Earth Initiative. This action aims to provide the technological and scientific support needed for the construction of antiseismic housing taking into consideration environmental, socio-cultural, and socio-economic sustainability as key factors for the project. Students from Kathmandu University are taking part in a series of experimental constructive actions in the town of Dhulikhel, aiming to provide a response to the major constructive problems and limitations of local housing (as starkly highlighted by the 2015 Ghorka earthquake). This paper aims to present the initial results of the project and some possible perspectives and actions to be specified in its final year. Basically, the design efforts are being aimed at the promotion of an architecture taking inspiration from local Nepalese architecture, as a sign of identity which is safer in the event of ground movement, and more sustainable in terms of production and execution than conventional constructions whose format and technology have been imported from Europe.
\end{abstract}

\section{ANTECEDENTS AND REASONS FOR THE PROJECT}

\subsection{Framework of the project}

The "House Nepal" project is one of the lines of action of the Centre for Development Cooperation (CCD) of Universitat Politècnica de València, Spain, which serves as the headquarters for developing R\&D\&I projects in the field of Studies on Development, International Cooperation, and applying Technology for Human Developments to reach Sustainable Design Goals.

These goals propose common responses for the major challenges facing the world at present: poverty, inequality, and sustainability. Therefore, this research should be relevant to securing these, while taking development cooperation into account.

In this regard, the project, led by F. Vegas with other researchers from UPV and the Nepalese Foundation Abari: Bamboo and Earth Initiative chiefly aims to provide scientific and technological support to the local Nepalese population, creating actions for training, dissemination, and empowerment of local specialists, in collaboration with the town of Dhulikhel and students from Kathmandu University.

\subsection{Nepal, the third poorest country in Asia}

The earthquake which devastated Nepal in 2015 was a major blow to one of the poorest countries in Asia (Figure 1). In continuous political transition for the last decade and heavily reliant an agricultural economy Nepal has suffered greatly as a result of this tragedy. Located between two Asian giants, India and China, Nepal's level of development is low, with around a quarter of the population living below the poverty line (in Asia this is only exceeded by Afghanistan and Tajikistan). Its main economic activity is agricultural, and $70 \%$ of the Nepalese population works in this sector. According to CIA data, in 2018 its GDP reached 24,589M.€, with a per capita GDP of $875 €$. In terms of the United Nations Human Development Index (HDI), used to measure the progress of a country and show the standard of living of its inhabitants, the Nepalese are shown to have a poor standard of living (with an updated index for 2018 of 0.574 , placing the country in position $147 / 183$ in ascending order of world poverty - UNDP 2018).

In addition to the weakness of its economy, corruption and political instability, Nepal faces major gender inequalities despite improvements in recent years. Serious deforestation problems are decimating the country's forests, and most of the country has suffered extreme natural disasters such as harsh winters, strong winds, landslides, torrential monsoons, floods, avalanches, and earthquakes.

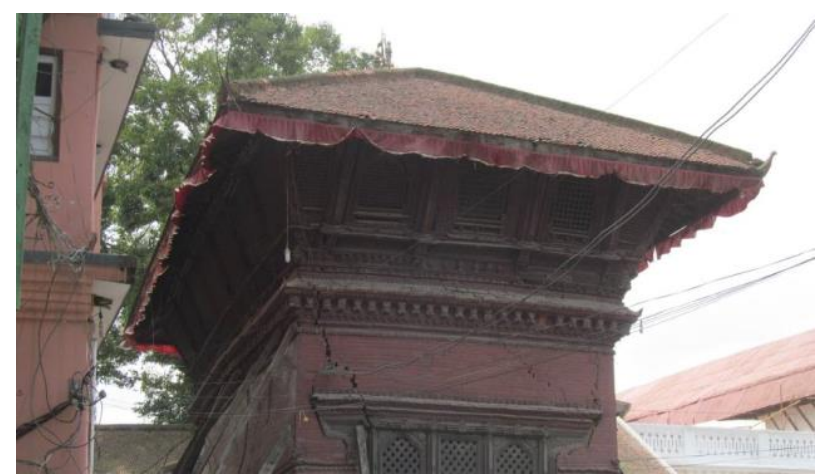

Figure 1 . Effects caused by 2015 Ghorka earthquake.

\footnotetext{
* Corresponding author
} 


\subsection{Local architecture between tradition and import}

The vernacular architecture of Nepal is rich and varied (Bernier, 1997; Gray, 2006). Almost three quarters of the current population of Nepal live in vernacular housing, built using local materials such as stone, wood, brick or earth in the form of rammed earth, adobe walls, mixed walls, or rendered wattle (CBS, 2014). Over the last thirty years successive governments have directly and indirectly encouraged the abandonment of this vernacular architecture moving towards a contemporary international architecture which uses reinforced concrete and metal structures (Figures 2 and 3). These imported materials, which do not always adapt to the local climatic conditions, were costly for local residents. In addition, the restriction in the use of timber due to the rampant deforestation of the country has led to it no longer being used for ring beams or ledgers in masonry walls, a practice which provided resistance to earthquakes (Yeomans, 1996). The 2015 Ghorka earthquake caused these vernacular buildings, when poorly constructed, to collapse in the same way as modern reinforced concrete buildings. In contrast, traditional and contemporary buildings that were well built with anti-seismic traditional timber or modern metal reinforcements successfully withstood the earthquake (Abari, 2016).
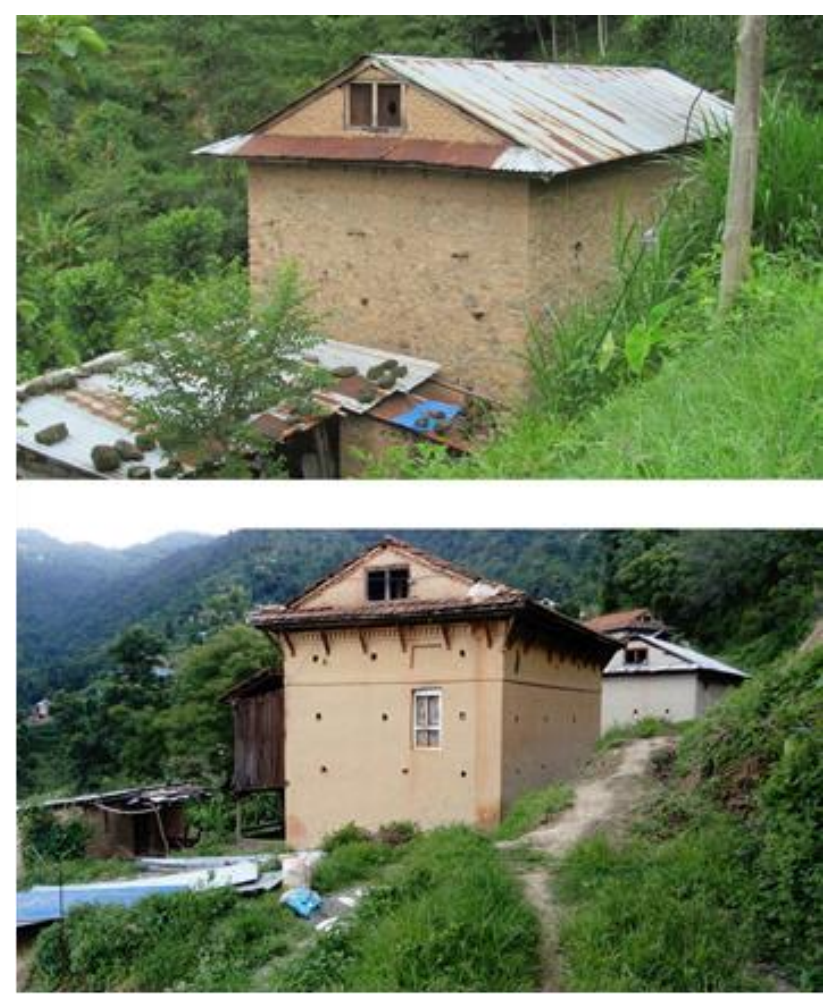

Figures 2 and 3. Dhulikhel:local traditional architecture and imported materials.

\subsection{The Abari foundation and its catalyst role}

The Abari, Bamboo and Earth Initiative foundation is an initiative committed to society and the environment (Figure 4). It designs and builds an architecture which studies, promotes, and celebrates vernacular architectural tradition in Nepal, especially using natural materials like earth and bamboo. This initiative, with a strong social component, has developed and built numerous houses, schools, and infrastructures which benefit the country. Following the 2015 earthquake, given the great number of homes in need of reconstruction and the scattered and isolated nature of most of the settlements affected, a dignified proposal was made for Owner Driven Reconstruction to encourage owners to implement seismic solutions in homes in earthquake-stricken regions. To do so, Abari drew up several manuals for the construction of provisional and permanent housing and schools which were made available to the public free of cost (Abari, 2016a, 2016b, 2016c, 2016d) (http://abari.earth/our-story/). These ideas have also been taken into consideration by the Nepalese government as part of its strategies for the reconstruction of the country.

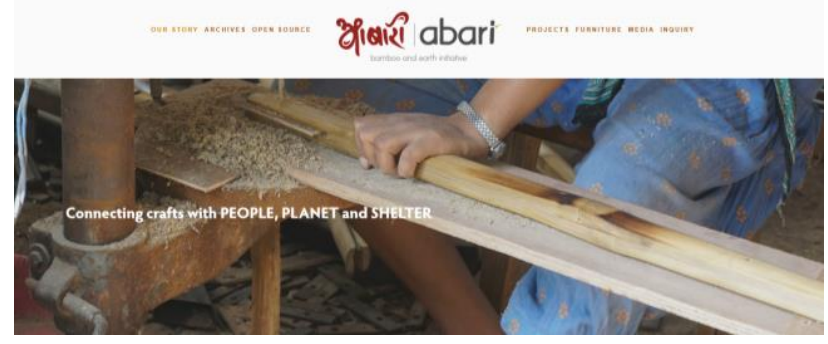

Figure 4. Details of Abari Foundation working approach.

\section{ANSWERS FOR NEPALESE BUILDINGS?}

\subsection{A critical scenario: the construction of housing in Nepal}

At present, the construction of housing in Nepal, both in connection with the usual demand and the still plentiful postseismic reconstruction work, is facing several problems. Most of the collapses of traditional buildings caused by earthquakes were due to a lack of structural integrity, roof collapses, foundation issues, poor building quality, or other issues affecting loadbearing walls. Most of these complications could have been avoided with the design of low buildings with thick rammed earth walls or compacted earth walls with a low centre of gravity, using traditional vertical and horizontal wood connectors incorporated into the masonry or earthen constructions, which have always been vital to resistance to earthquakes (Abari, 2016).
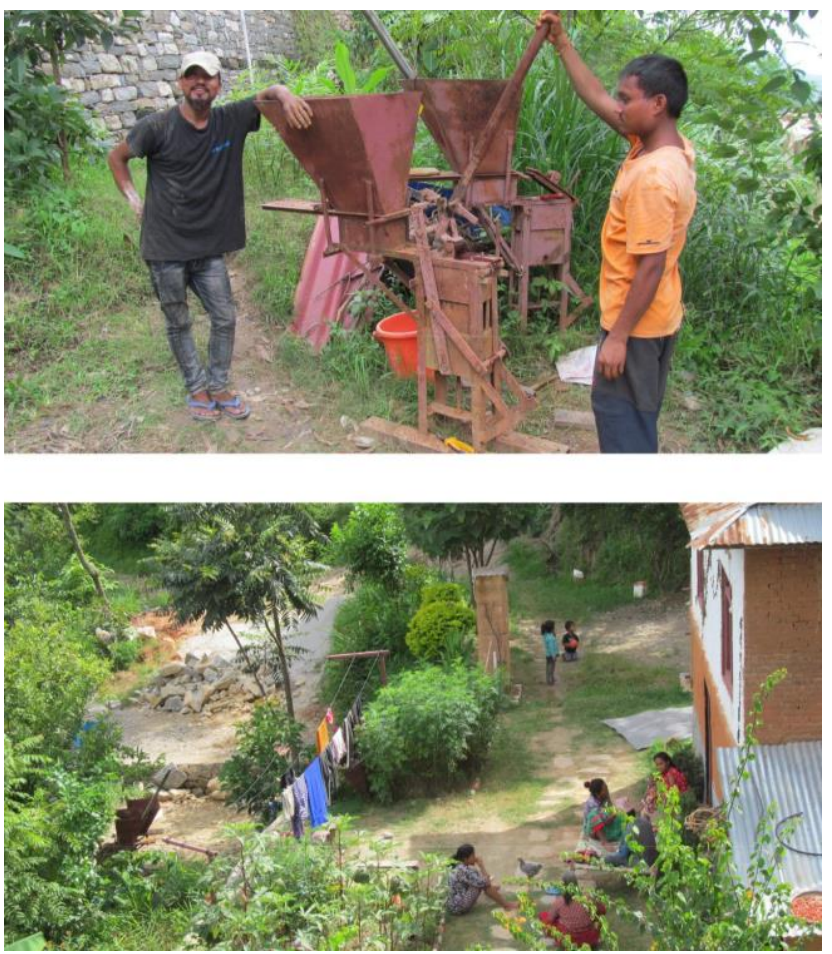

Figures 5 and 6. Dhulikhel: local production of CEB. 
However, these traditional wood ledgers have gradually been abandoned due to impediments from the government, which is taking steps to ensure the conservation of the country's forests. This has brought about the gradual appearance of imported solutions incorporating polypropylene meshes between several courses (Adhikary, 2016), galvanized steel bands, and metallic containment gabions (Langenbach, 2015), combining local materials and techniques with minor contributions from external materials.

Thanks to these solutions the use of timber as an interior connection in walls is avoided to a large extent, although this material is still needed for the construction of floors and roofs. This creates a pressing need to think about a housing prototype which may be able to withstand these issues.

\subsection{The proposal: homes without wood or imported materials}

With this diagnosis and conditioning factors in mind, the "House Nepal" project proposes the creation of a timber-free housing prototype with $0 \mathrm{~km}$ materials, or failing that, cheap materials which can be locally sourced with little or no processing, so that they are environmentally friendly.

The starting point for the options is the construction of earthen walls, which are traditional in Nepal, in the form of rammed earth or CEB or Compressed Earth Block walls, in a modern reinterpretation of adobe (Figures 5 and 6). CEBs are obtained by compacting a mix of local earth and approximately $5 \%$ of bonding agent (lime or cement), avoiding calcination and fuel costs so that it is harmless to the environment. The possibility of using ceramic brick tile vaults (Moya, 1947; Fortea, 2001; Davis, 2012) or CEBs (Ramage, 2010; Block et al., 2010) for work on the floors and ceilings is being considered.

Up to now "only" prior studies have been executed for techniques, materials, modelling, and laboratory tests, although the construction of housing prototypes is planned for the town of Dhulikhel in 2020: The local population will also be involved in awareness and dissemination activities, and training provided for students of Kathmandu University.

\section{ACTIONS UNDERWAY}

\subsection{Constructive and design actions}

In spring 2020 construction and experimentation is expected to take place with a $4 \times 4 \mathrm{~m}$ habitation module to be added to other similar ones to form a housing unit which does not require wood to guarantee stability and construction and is also able to withstand the seismic movements which affect the country (Figures 7, 8 and 9). Experimentation will be carried out with the following materials to find the best possible solutions from all perspectives: loadbearing walls (rammed earth, CEBs or recycled materials) tile vaults (brick, $\mathrm{CEB}$ ) and reinforcement mesh (jute, hemp, recycled plastic). The options studied will be aggregation, bond, intrinsic resistance, durability, and the ability to withstand earthquakes.

The autonomy and amount of resources and human means to guarantee maximum empowerment of the local population will also be studied. This will include women, who could carry out vital work producing reinforcement meshes with jute or hemp fibres, or recycled plastic strips, awarding them a frontline role in a country where they have been ignored.
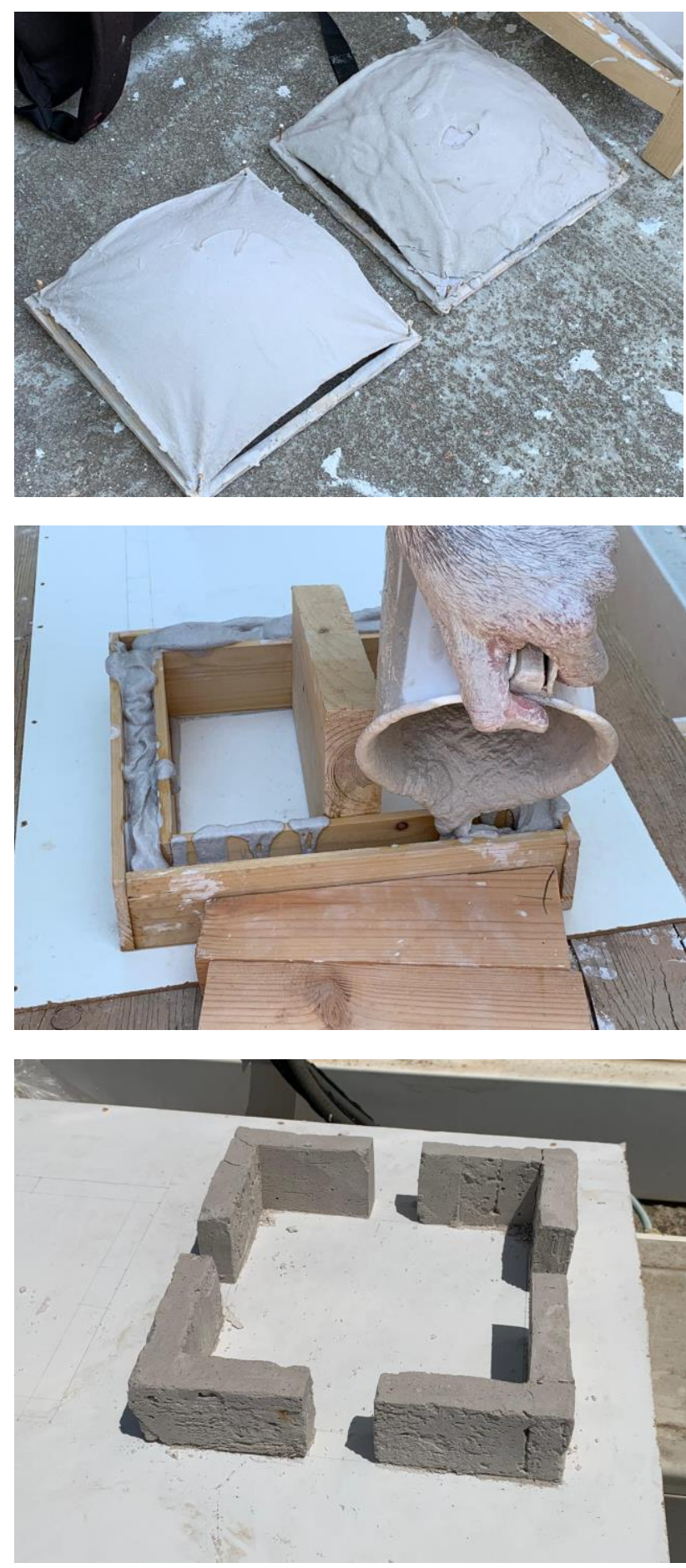

Figures 7, 8 and 9. First models for housing unit design (walls+vaults).

\subsection{Socio-cultural empowerment actions}

This project is proposed as a participatory process, involving the entire population of Dhulikhel -children, women, and men - in keeping with what the Abari Foundation has developed in recent years, empowering local residents in the construction and reconstruction of housing and buildings destroyed in the 2015 Ghorka earthquake. The project aims to support the one set up by the Abari Foundation for Owner Driven Reconstruction to avoid the import of standardized models and foreign technology, as well as delays in the construction and occupation of housing. 


\subsection{Educational and technical training actions}

Courses geared towards the students of Kathmandu University will be included in the framework of the campaign for Dhulikhel in spring 2020. These courses will examine technical training, both with walls with plant mesh, and the technological and scientific training for the construction of tile vaults with similar reinforcements.

This specific high quality scientific and technical training is based on theoretical-practical courses and the execution of walls and vaults reinforced with mesh like that of the housing prototype; it will allow local young people to learn a technique which uses local materials to improve on technology and which will be used beyond the construction of this housing in other buildings in these towns, or even in other parts of the country.
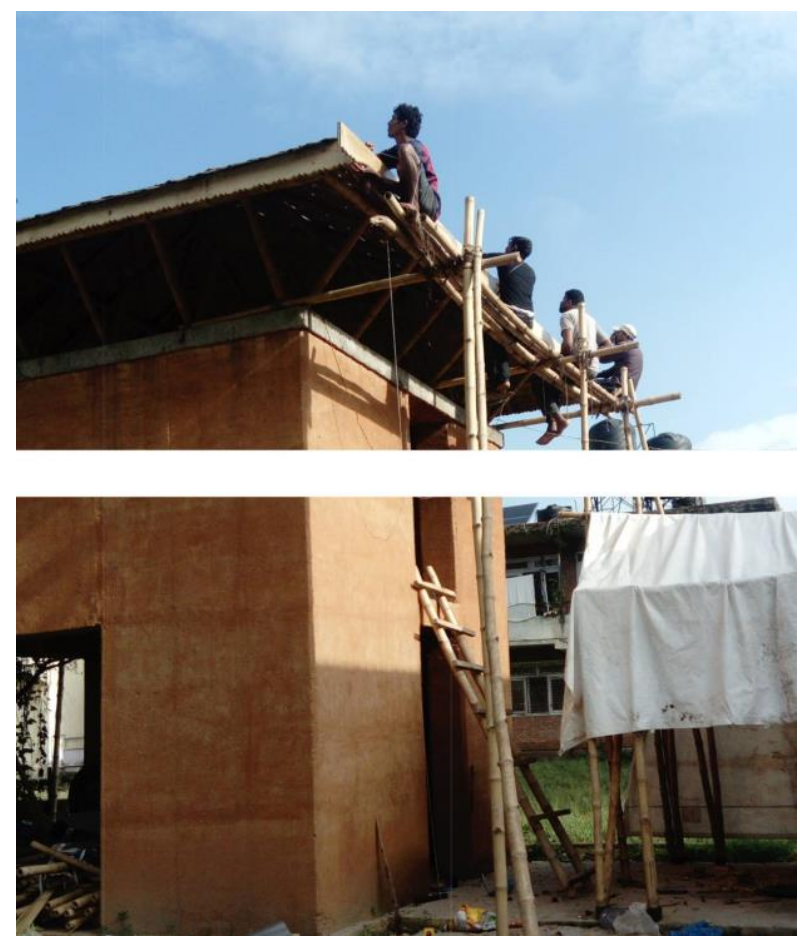

Figure 10. Examples of Abari,

Bamboo and Earth Initiative foundation projects.

\section{CONCLUSIONS}

The "House Nepal" project proposes a holistic approach to the issue of sustainable housing, simultaneously considering social, economic, and environmental aspects. In social terms, residents are involved, traditional construction methods are preserved with improved resistance to earthquakes using simple strategies and local materials. From an economic viewpoint, construction costs are brought down and chiefly transferred to labour and simple work tools, with the possibility of improving and maintaining these homes in the future, using old-new technology from the prototype as a professional way to earn a living. In environmental terms, the impact of construction is minimized through the use of natural materials, taking advantage of daylight and the excellent insulation provided by the natural thermal inertia of earth.

\section{ACKNOWLEDGEMENTS}

This paper is part of the "HouSe-Nepal: prototipo de vivienda sostenible anti-seísmo en Nepal" project, funded by the CCD/UPV Adsideo- Cooperación 2018 programme. https://housenepal.blogs.upv.es/

The photographs in the paper belong to Asís Casañs Tejedor, to whom we are thankful.

\section{REFERENCES}

AA.VV. 2018: Índices e indicadores de desarrollo humano, Actualización estadística de 2018, UNDP Org Ed.

(http://hdr.undp.org/sites/default/files/2018_human_developme nt_statistical_update_es.pdf)

Abari. 2016a: How to build a transitional shelter: http://abari.earth/

Abari. 2016b: How to build a permanent home: http://abari.earth/

Abari. 2016c: Model homes: http://abari.earth/

Abari. 2016d: How to build a transitional class.: http://abari.earth/

Adhikary, N. 2016: "Vernacular architecture in post-earthquake Nepal" in International Journal of Environmental Studies vol. 73, Issue 4, https://doi.org/10.1080/00207233.2016.1179011

Bernier, MR. 1997: Himalayan Architecture. Ass. University press, London

Block, P. et al. 2010: "Tile vaults for low-cost construction in Africa" in Journal of the African Technology 7/1-2, 4-13, Taylor and Francis Ed., London

CBS 2014: Annual household survey 2014. Gov.Nepal Ed.. Katmandú

Davis, L. 2012: "Funicular Tile Vaults" in Structural Engin.11 46-56, ASCE Ed., Michigan

Fortea M., López, V. 2001: Bóvedas de ladrillo. Ed.Oficios, Madrid

Gray, J. 2006: Architecture of lifeworlds, Nepal, Aldershot: Ashgate, UK

Langenbach, R. 2015: "Gabion bands" for reconstructing rural rubble stone houses after the 2015 Nepal earthquakes", Report: https://www.traditional-is-modern.net/NEPAL/RLCorrespondance Reports/ReconstructingRuralStoneHouses(Langenbach)v2.pdf

Moya, L. 1947: Bóvedas tabicadas. Madrid, Ministerio de Fomento Ed., Madrid

Ramage M. et al. 2010: "African vaults with soil-cement tiles". In Journal Shell \& Spatial Structures, 51/4, 14-23, IASS Ed., Madrid

Yeomans, D. 1996: The Interaction of Timber and Brick Masonry in the Kathmandu Valley, APT Bull0etin, 1/2, 74-81 